\title{
Oral Hypoglycemics: Increased Postoperative Mortality in Coronary Risk Patients
}

\author{
Raban V. Jeger Manfred D. Seeberger Ulrich Keller Matthias E. Pfisterer \\ Miodrag Filipovic \\ Departments of Cardiology, Anesthesia, and Endocrinology, Diabetes and Clinical Nutrition, University Hospital, \\ Basel, Switzerland
}

\section{Key Words}

Diabetes mellitus - Coronary artery disease $\cdot$ Hypoglycemic agents $\cdot$ Insulin $\cdot$ Mortality

\begin{abstract}
Background: Diabetes mellitus (DM), particularly if insulindependent, is a predictor of increased perioperative risk, whereas stringent metabolic control with insulin is beneficial in the critically ill. Methods: The impact of oral hypoglycemics $(\mathrm{OH})$ vs. insulin on outcome was determined as a secondary retrospective analysis of a cohort study in patients with coronary artery disease (CAD) and DM undergoing major non-cardiac surgery. Primary end-point was 2-year allcause mortality; secondary endpoints were perioperative myocardial ischemia and 2-year cardiac mortality. Results: Of 173 patients, DM was diagnosed in 42 (24\%) based on preexisting treatment with $\mathrm{OH}(15 \%)$ or insulin (9\%). During follow-up, 40/173 (23\%) patients died. All-cause mortality was similar in the non-diabetic (20\%) and insulin groups (19\%) but significantly higher in the $\mathrm{OH}$ group (42\%; $\mathrm{p}=0.025$ ). Cardiac mortality tended to be higher in the $\mathrm{OH}$ group compared with the insulin and non-diabetic groups ( 27 vs. $19 \%$
\end{abstract}

This study was presented in part at the Annual Meeting of the American College of Cardiology, Chicago, March 30, 2003.
(C) 2007 S. Karger AG, Basel

0008-6312/07/1074-0296\$23.50/0

Fax +41613061234 E-Mail karger@karger.ch www.karger.com
Accessible online at:

www.karger.com/crd and $11 \%$, respectively; $\mathrm{p}=0.066)$. Multivariate analysis revealed renal failure (odds ratio $[\mathrm{OR}]=4.9,95 \%$ confidence interval $[\mathrm{Cl}]=1.8-13.0)$, treatment with $\mathrm{OH}(\mathrm{OR}=3.3,95 \%$ $\mathrm{Cl}=1.2-9.0)$, peripheral vascular surgery $(\mathrm{OR}=2.7,95 \%$ $\mathrm{Cl}=1.2-6.0)$, and prior diuretic therapy $(\mathrm{OR}=2.6,95 \% \mathrm{Cl}=$ 1.1-5.7) being independently associated with 2-year allcause death. No difference existed in postoperative ischemia among the different groups. Conclusions: Long-term mortality after major non-cardiac surgery is elevated in patients with CAD and diabetes mellitus only if they are treated with $\mathrm{OH}$, but not if they are treated with insulin. Further evaluation of the impact of perioperative anti-diabetic treatment on morbidity and mortality in CAD is warranted.

Copyright $\odot 2007$ S. Karger AG, Basel

\section{Introduction}

Type 2 diabetes mellitus (DM) is a significant health problem worldwide, affecting $4-6 \%$ of the population [1, 2]. While DM is an important risk factor for the development of coronary artery disease (CAD) [3], the outcome of CAD is poorer in patients with DM than in those without DM $[4,5]$.

While tight perioperative metabolic control improves postoperative outcome [6,7], the influence of the type of preoperative hypoglycemic therapy on outcome in pa-

Miodrag Filipovic, MD

Department of Anesthesia

University Hospital Basel

$\mathrm{CH}-4031$ Basel (Switzerland)

Tel. +41 6126525 25, Fax +41 6126573 20, E-Mail mfilipovic@uhbs.ch 
tients with DM and known or suspected CAD undergoing non-cardiac surgery is not known. Insulin treatment is an independent predictor of cardiac risk after major non-cardiac surgery [8]. Consequently, current guidelines for perioperative cardiovascular evaluation describe $\mathrm{DM}$ as a predictor of risk for cardiac complications particularly if insulin-treated [9]. Nevertheless, the effects of oral hypoglycemics $(\mathrm{OH})$ on perioperative outcome have not been sufficiently evaluated. This is surprising as there are conflicting results concerning cardiovascular mortality in non-surgical patients with and without documented CAD treated with $\mathrm{OH}[4,10-14]$. In contrast, insulin treatment combined with a strict blood glucose control reduces mortality in critically ill patients [7] and in patients with acute myocardial infarction [15-17]. However, mortality from myocardial infarction was not decreased when glucose levels failed to be lowered by intense insulin therapy [18]. The aim of this analysis was to determine the impact of DM and its treatment strategy (OH vs. insulin) on long-term outcome in patients with documented or highly suspected CAD undergoing major non-cardiac surgery.

\section{Materials and Methods}

\section{Subjects and Definitions}

This is a secondary analysis of a prospective observational cohort study of preoperative risk stratification in patients with or at risk for CAD $[19,20]$. The local institutional review board approved the study protocol, and each of the patients gave informed written consent. In brief, patients were eligible if they had known or suspected CAD, and were scheduled for major non-cardiac surgery defined as abdominal aortic surgery, peripheral vascular surgery of the lower limb, laparotomy, major orthopedic surgery, thoracotomy, and major surgery of the neck. CAD was considered as documented if patients had myocardial ischemia in dobutamine stress echocardiography or dipyridamole thallium imaging, significant stenoses in a previous coronary angiography, a prior myocardial infarction, or prior myocardial revascularization; CAD was considered as suspected if patients had typical angina or if vascular surgery was planned and $\geq 2$ of the following criteria were present: age $>70$ years, hypertension, DM, prior stroke, impaired exercise tolerance, or a pathologic resting ECG. DM was diagnosed if patients were treated with insulin or $\mathrm{OH}$ at admission; some of the patients may have been diabetic based on their blood glucose levels, but were analyzed as non-diabetics due to lacking drug treatment. Renal failure was defined as a calculated creatinine clearance of $<30 \mathrm{ml} / \mathrm{min}$.

\section{Methods}

Continuous ECG recording (Marquette Series 8500, Marquette Electronics, Milwaukee, Wisc., USA) was started before induction of anesthesia and continued for $48 \mathrm{~h}$, and ST segment depressions of $\geq 2 \mathrm{~mm} \geq 1 \mathrm{~min}$ were considered as significant.
Cardiac troponin I was measured on the first and second day after surgery using a commercially available kit $\left(\mathrm{AxSYM}^{\circledR}, \mathrm{Abbott}, \mathrm{Ab}\right.$ bott Park, Ill., USA) with the normal upper limit of $2 \mu \mathrm{g} / \mathrm{l}$ specified by the manufacturer. Glucose levels were assessed preoperatively in all patients in a fasting state, but postoperatively only in diabetic patients using enzymatic methods (Roche Diagnostics, Basel, Switzerland). Interventions for establishing perioperative metabolic control were not pre-specified and left to the discretion of the physicians in charge.

\section{Endpoints and Follow-Up}

The primary endpoint was all-cause mortality after 2 years; secondary endpoints were cardiac mortality after 2 years, and evidence of perioperative myocardial ischemia (cardiac troponin I $>2 \mu \mathrm{g} / \mathrm{l}$ and ST segment depressions $\geq 2 \mathrm{~mm} \geq 1 \mathrm{~min}$ in the first 2 days after surgery). Semistructured follow-up interviews were performed by telephone at 6,12 , and 24 months after surgery. Cause of death was obtained from the Swiss Mortality Registry (Federal Statistical Office, Bern, Switzerland).

\section{Statistical Analysis}

Statistical analysis was performed using Stat View ${ }^{\circledR}$ software version 5.0.1 (SAS Institute Inc., Cary, N.C., USA). Continuous data were analyzed using the Mann-Whitney $U$ and KruskalWallis tests, and categorical data using Fisher's exact and $\chi^{2}$ tests, where appropriate. All continuous data were expressed as median values with their range. Multivariate analysis using logistic regression was done considering baseline variables with an initial $\mathrm{p}<0.05$. Single variables were removed in a stepwise method until the model met a 0.05 significance level in all variables. Survival was compared using Kaplan-Meier survival curves and logrank test. $P$ values were two-sided and considered to indicate statistical significance if $<0.05$.

\section{Results}

DM was diagnosed in $42(24 \%)$ patients from whom $26(15 \%)$ were chronically treated with $\mathrm{OH}$ (OH group) and 16 (9\%) with insulin only (insulin group). In the $\mathrm{OH}$ group, 17 patients received sulfonylureas, 2 metformin, and 1 repaglinide as only $\mathrm{OH}$ drug. Six patients received a combination of sulfonylureas and metformin. Three patients treated with $\mathrm{OH}$ and insulin were analyzed as part of the $\mathrm{OH}$ group. Baseline characteristics are shown in table 1. Levels of $\mathrm{HbA}_{1 \mathrm{c}}$ tended to be higher in patients treated with insulin, but were similar in patients with DM treated with $\mathrm{OH}$ and non-diabetic patients. Patients without DM had lower preoperative blood glucose levels than patients with DM, but glucose levels differed neither before nor after surgery in the two DM groups. No difference existed in postoperative ischemia among the different groups (table 2). All-cause mortality tended to be higher in diabetic than in non-diabetic patients (33 vs. $20 \%, p=0.059)$, and was similar in insulin-treated $(19 \%)$ 
Table 1. Baseline characteristics

\begin{tabular}{|c|c|c|c|c|c|}
\hline & $\begin{array}{l}\text { All } \\
(n=173)\end{array}$ & $\begin{array}{l}\text { No DM } \\
(\mathrm{n}=131)\end{array}$ & $\begin{array}{l}\mathrm{OH} \\
(\mathrm{n}=26)\end{array}$ & $\begin{array}{l}\text { Insulin } \\
(n=16)\end{array}$ & $\mathrm{p}^{*}$ \\
\hline Age, years & $73(47-89)$ & $73(47-89)$ & $75(52-84)$ & $72(50-77)$ & 0.29 \\
\hline Female & 33 & 31 & 31 & 56 & 0.11 \\
\hline Body mass index, $\mathrm{kg} / \mathrm{m}^{2}$ & $25(14-38)$ & $25(14-37)$ & $26(21-33)$ & $28(19-38)$ & 0.24 \\
\hline Creatinine clearance, $\mathrm{ml} / \mathrm{min}$ & $70(5-176)$ & $67(5-176)$ & $73(16-144)$ & $77(9-133)$ & 0.71 \\
\hline Renal failure & 15 & 16 & 8 & 19 & 0.50 \\
\hline Hypertension & 69 & 66 & 65 & 81 & 0.17 \\
\hline Current smoking & 25 & 39 & 19 & 13 & 0.29 \\
\hline Hypercholesterolemia $(n=167)$ & 57 & 60 & 58 & 50 & 0.86 \\
\hline Angina pectoris & 31 & 33 & 24 & 31 & 0.62 \\
\hline Shortness of breath & 60 & 61 & 50 & 62 & 0.56 \\
\hline History of myocardial infarction & 51 & 55 & 50 & 19 & 0.02 \\
\hline Prior revascularization & 29 & 34 & 31 & 6 & 0.03 \\
\hline History of congestive heart failure & 13 & 11 & 23 & 19 & 0.19 \\
\hline Ongoing malignant disease & 25 & 27 & 19 & 13 & 0.33 \\
\hline \multicolumn{6}{|l|}{ Drug therapy } \\
\hline Acetylic salicylic acid & 59 & 61 & 50 & 56 & 0.56 \\
\hline Coumadin & 19 & 15 & 35 & 25 & 0.06 \\
\hline Diuretics & 37 & 36 & 46 & 50 & 0.25 \\
\hline Inhibitors of ACE & 35 & 32 & 46 & 44 & 0.29 \\
\hline Beta-blockers & 34 & 38 & 15 & 31 & 0.08 \\
\hline Ca-antagonists & 27 & 26 & 27 & 31 & 0.90 \\
\hline Long-acting nitrates & 20 & 18 & 23 & 25 & 0.73 \\
\hline Digoxin & 8 & 8 & 15 & 0 & 0.19 \\
\hline Amiodarone & 5 & 6 & 0 & 6 & 0.43 \\
\hline \multicolumn{6}{|l|}{ Surgery } \\
\hline ASA classification & & & & & 0.56 \\
\hline ASA II & 9 & 11 & 4 & 0 & \\
\hline ASA III & 81 & 79 & 84 & 88 & \\
\hline ASA IV & 10 & 10 & 12 & 12 & \\
\hline Emergency surgery & 2 & 2 & 4 & 0 & 0.72 \\
\hline Abdominal aortic surgery & 34 & 37 & 35 & 6 & 0.046 \\
\hline Peripheral vascular surgery of the lower limb & 32 & 24 & 46 & 69 & 0.0004 \\
\hline Laparotomy & 23 & 27 & 8 & 13 & 0.06 \\
\hline Major orthopedic surgery & 8 & 8 & 8 & 13 & 0.79 \\
\hline Thoracotomy & 2 & 3 & 0 & 0 & 0.52 \\
\hline Major surgery of the neck & 1 & 1 & 4 & 0 & 0.37 \\
\hline
\end{tabular}

Values are median values with range or \% of patients.

* Kruskal-Wallis test for continuous, $\chi^{2}$ test for categorical variables.

$\mathrm{ACE}=$ Angiotensin-converting enzyme; $\mathrm{ASA}=$ American Society of Anesthesiologists; $\mathrm{CrCl}=$ creatinine clearance; $\mathrm{DM}=$ diabetes mellitus; $\mathrm{OH}=$ oral hypoglycemics.

and non-diabetic patients but significantly higher in patients with $\mathrm{OH}$ ( $42 \%$; $\mathrm{p}=0.025$; fig. 1$)$. Cardiac mortality was higher in diabetic than in non-diabetic patients $(24$ vs. $11 \%, p=0.037$ ), and tended to be higher in the $\mathrm{OH}$ group (27\%) than in the insulin group (19\%) and in nondiabetic patients $(\mathrm{p}=0.066)$. In univariate analysis pre- dictors of death were age $>70$ years, hypertension, renal failure, history of congestive heart failure, treatment with $\mathrm{OH}$ and diuretics, aortic surgery, and peripheral vascular surgery. Independent predictors of death were renal failure, peripheral vascular surgery, and treatment with $\mathrm{OH}$ and diuretics (table 3). 
Table 2. Perioperative management, metabolic control, and ischemia

\begin{tabular}{|c|c|c|c|c|c|}
\hline & $\begin{array}{l}\text { All } \\
(\mathrm{n}=173)\end{array}$ & $\begin{array}{l}\text { No DM } \\
(n=131)\end{array}$ & $\begin{array}{l}\mathrm{OH} \\
(\mathrm{n}=26)\end{array}$ & $\begin{array}{l}\text { Insulin } \\
(\mathrm{n}=16)\end{array}$ & $\mathrm{p}^{*}$ \\
\hline \multicolumn{6}{|c|}{ Perioperative hypoglycemic therapy, \% } \\
\hline Intraoperative insulin & - & - & 14 & 58 & 0.016 \\
\hline Postoperative insulin & - & - & 19 & 62 & 0.025 \\
\hline Insulin $1^{\text {st }}$ day after surgery & - & - & 19 & 92 & $<0.0001$ \\
\hline Insulin $2^{\text {nd }}$ day after surgery & - & - & 29 & 92 & 0.0004 \\
\hline Insulin $3^{\text {rd }}$ day after surgery & - & - & 14 & 92 & $<0.0001$ \\
\hline Insulin at discharge & - & - & 15 & 100 & $<0.0001$ \\
\hline $\mathrm{OH} 1^{\text {st }}$ day after surgery & - & - & 33 & 0 & 0.029 \\
\hline $\mathrm{OH} 2^{\text {nd }}$ day after surgery & - & - & 48 & 0 & 0.0049 \\
\hline $\mathrm{OH} 3^{\text {rd }}$ day after surgery & - & - & 52 & 0 & 0.0018 \\
\hline $\mathrm{OH}$ at discharge & - & - & 80 & 0 & $<0.0001$ \\
\hline \multicolumn{6}{|c|}{ Perioperative metabolic control, \% and mmol/l, respectively } \\
\hline $\operatorname{HbA}_{1 \mathrm{c}}(\mathrm{n}=15)$ & $7.3(5.1-10.2)$ & $6.6(5.9-7.9)$ & $6.7(5.1-8.8)$ & $8.5(6.4-10.2)$ & 0.087 \\
\hline Glucose day before surgery & $6.3(3.6-16.5)$ & $6.2(3.9-14.0)$ & $7.8(3.6-14.6)$ & $7.9(6.2-16.5)$ & 0.0002 \\
\hline Glucose $1^{\text {st }}$ day after surgery & - & - & $7.8(5.0-12.5)$ & $9.6(5.4-22.8)$ & 0.22 \\
\hline Glucose $2^{\text {nd }}$ day after surgery & - & - & $8.1(4.6-12.3)$ & $8.2(4.4-20.1)$ & 0.45 \\
\hline Glucose $3^{\text {rd }}$ day after surgery & - & - & $7.9(4.5-12.0)$ & $7.6(3.9-15.8)$ & 0.88 \\
\hline \multicolumn{6}{|c|}{ Postoperative ischemia (days 1 and 2), \% } \\
\hline Elevated cardiac troponin I & 16 & 15 & 25 & 15 & 0.55 \\
\hline ST depressions $(n=117)$ & 46 & 42 & 50 & 63 & 0.24 \\
\hline
\end{tabular}

Values are median values with range or \% of patients.

* Mann-Whitney U test and Kruskal-Wallis test for continuous, Fisher's test, and $\chi^{2}$ test for categorical variables, where appropriate. $\mathrm{DM}=$ Diabetes mellitus; $\mathrm{OH}=$ oral hypoglycemics.

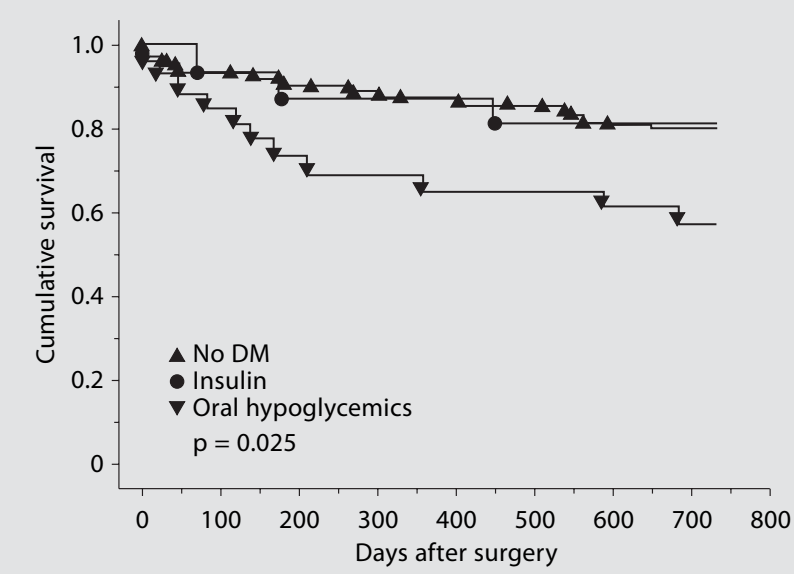

Postoperative Mortality in CAD and Oral Hypoglycemics-Treated Diabetes
Table 3. Multivariate predictors of 2-year all-cause mortality

\begin{tabular}{lllrl}
\hline & OR & 95\% CI & $\chi^{2}$ & $\mathrm{p}$ \\
\hline Renal failure & 4.9 & $1.8-13.0$ & 10.2 & 0.0014 \\
Oral hypoglycemic treatment & 3.3 & $1.2-9.0$ & 5.3 & 0.021 \\
Peripheral vascular surgery & 2.7 & $1.2-6.0$ & 5.6 & 0.018 \\
Diuretic treatment & 2.6 & $1.1-5.7$ & 5.2 & 0.022 \\
\hline \multicolumn{2}{c}{ CI = Confidence interval; OR = odds ratio. } \\
\hline
\end{tabular}

Fig. 1. Kaplan-Meier survival curves for patients without DM and for patients with DM treated with insulin and $\mathrm{OH}$, respectively ( $\mathrm{p}=0.025$, log-rank test). 


\section{Discussion}

This study performed in diabetic patients with documented or suspected CAD undergoing major non-cardiac surgery found that treatment with $\mathrm{OH}$ was an independent predictor of 2-year all-cause mortality. In contrast, patients treated with insulin had the same outcome as patients without DM. This finding was unexpected as current guidelines and risk indices consider DM as a risk factor particularly if treated with insulin. Previous data show that tight metabolic control, as reflected by normoglycemia, in both diabetic and non-diabetic patients with critical diseases, was related to beneficial outcome $[18,21]$. Our data do not provide an explanation for this finding, which could reflect either a beneficial effect of insulin or a detrimental effect of $\mathrm{OH}$. Potential beneficial effects of insulin are better metabolic control, antiinflammatory and anti-atherogenic effects, and beneficial effects on intracellular mechanisms in the ischemic myocardium $[22,23]$. However, metabolic glucose control in the insulin group was not better than in the $\mathrm{OH}$ group, as could have been expected. In addition, up to $50 \%$ of the patients in the $\mathrm{OH}$ group received insulin during and early after surgery and, thus, were at least partially exposed to the potential beneficial effects of insulin. Thus, it is unlikely that our findings can be explained by the beneficial effects of insulin but might reflect potentially deleterious effects of $\mathrm{OH}$ as administered before surgery. Sulfonylureas prevent ischemic preconditioning by inhibiting cardiac KATP-channels [24]. As perioperative myocardial ischemia is common in CAD patients and associated with unfavorable outcome [20,25], one can hypothesize that this inhibition prior to surgery might have caused the observed difference in mortality rates post surgery. However, not consistent with this hypothesis, were the similar incidences of perioperative myocardial ischemia (i.e., elevation of cardiac troponin I and ST segment depression) in all study groups. This latter finding and the lack of statistically significant differences in cardiac mortality among the study groups suggest that the higher all-cause mortality in $\mathrm{OH}$ treated patients might have been caused only partially by cardiac side effects. The multivariate analysis revealed renal failure, treatment with diuretics, and peripheral vascular surgery as additional independent predictors of 2-year all-cause mortality. Both renal failure [8] and peripheral vascular surgery [26] are known risk factors for perioperative mortality, while preoperative treatment with diuretics might be a surrogate for underlying hypertension and congestive heart failure, which were both associated with adverse outcome in the univariate analysis.

Our study has several limitations. First, it was a secondary analysis of prospectively collected data. Second, the number of patients with DM was too small to allow for final conclusions and data on the duration of DM and late diabetic complications were missing. Nevertheless, the study was large enough to clearly identify $\mathrm{OH}$-treated $\mathrm{DM}$ as an independent predictor of all-cause mortality in our cohort, and it is unlikely that this result happened by chance. Third, the study groups were not identical regarding patient characteristics. However, the higher rate of peripheral vascular surgery and the lower rate of prior myocardial infarction with revascularization in the insulin group would have been more consistent with a higher and not a lower mortality, because mortality in peripheral vascular surgery is expected to be the highest $[9,27]$ and prior revascularization might provide a better postoperative survival $[9,28]$.

\section{Conclusion}

In conclusion, our study indicates that chronic treatment with $\mathrm{OH}$ but not with insulin was associated with elevated long-term mortality in diabetic CAD patients after major non-cardiac surgery. This finding might have been caused by either a beneficial effect of insulin per se, or a detrimental effect of $\mathrm{OH}$ during and after surgery. Due to the nature of our analysis and the limitations of our study, our data is hypothesis-generating rather than hypothesis-proving. Because of the high numbers of $\mathrm{OH}-$ treated patients that undergo non-cardiac surgery and the potentially high impact on outcome, our findings identify an urgent need for additional prospective trials to clarify the optimal perioperative treatment strategy in patients with DM. Meanwhile, $\mathrm{OH}$-treated DM should be considered as an equivalent risk factor for adverse outcome as insulin-treated DM.

\section{Acknowledgments}

The authors thank Olivia Dergeloo, RN, Ingrid Frölich, RN, Reinhard Rohlfs, RN, Esther Seeberger, RN, and Claudia Werner, $\mathrm{RN}$, for technical assistance, and Joan Etlinger, BA, for editorial assistance.

Supported by the Department of Anesthesia, University Hospital, Basel, Switzerland. 


\section{References}

1 Inzucchi SE: Oral antihyperglycemic therapy for type 2 diabetes: scientific review. JAMA 2002;287:360-372.

$\checkmark 2$ Meisinger C, Thorand B, Schneider A, Stieber J, Doring A, Lowel H: Sex differences in risk factors for incident type 2 diabetes mellitus: the MONICA Augsburg cohort study. Arch Intern Med 2002;162:82-89.

$\checkmark 3$ Wilson PW: Established risk factors and coronary artery disease: the Framingham Study. Am J Hypertens 1994;7:7S-12S.

$\checkmark 4$ Rytter L, Troelsen S, Beck-Nielsen H: Prevalence and mortality of acute myocardial infarction in patients with diabetes. Diabetes Care 1985;8:230-234.

5 Wackers FJ, Zaret BL: Detection of myocardial ischemia in patients with diabetes mellitus. Circulation 2002;105:5-7.

-6 Finney SJ, Zekveld C, Elia A, Evans TW: Glucose control and mortality in critically ill patients. JAMA 2003;290:2041-2047.

-7 van den Berghe G, Wouters P, Weekers F, Verwaest C, Bruyninckx F, Schetz M, Vlasselaers D, Ferdinande P, Lauwers P, Bouillon $\mathrm{R}$ : Intensive insulin therapy in critically ill patients. N Engl J Med 2001;345:1359-1367.

$\checkmark 8$ Lee TH, Marcantonio ER, Mangione CM, Thomas EJ, Polanczyk CA, Cook EF, Sugarbaker DJ, Donaldson MC, Poss R, Ho KKL, Ludwig LE, Pedan A, Goldman L: Derivation and prospective validation of a simple index for prediction of cardiac risk of major noncardiac surgery. Circulation 1999;100:10431049.

-9 Eagle KA, Berger PB, Calkins H, Chaitman BR, Ewy GA, Fleischmann KE, Fleisher LA, Froehlich JB, Gusberg RJ, Leppo JA, Ryan T, Schlant RC, Winters WL, Gibbons RJ, Antman EM, Alpert JS, Faxon DP, Fuster V, Gregoratos G, Jacobs AK, Hiratzka LF, Russell RO, Smith SC: ACC/AHA guideline update for perioperative cardiovascular evaluation for noncardiac surgery - executive summary. A report of the American College of Cardiology/American Heart Association Task Force on Practice Guidelines (Committee to Update the 1996 Guidelines on Perioperative Cardiovascular Evaluation for Noncardiac Surgery). Circulation 2002;105: 1257-1267.

-10 Meinert CL, Knatterud GL, Prout TE, Klimt CR: A study of the effects of hypoglycemic agents on vascular complications in patients with adult-onset diabetes. II. Mortality results. Diabetes 1970;19:789-830.
11 The University Group Diabetes Program: A study of the effects of hypoglycemic agents on vascular complications in patients with adult- onset diabetes. V. Evaluation of phenformin therapy. Diabetes 1975;24:65-184.

12 Garratt KN, Brady PA, Hassinger NL, Grill DE, Terzic A, Holmes DR Jr: Sulfonylurea drugs increase early mortality in patients with diabetes mellitus after direct angioplasty for acute myocardial infarction. J Am Coll Cardiol 1999;33:119-124.

13 UK Prospective Diabetes Study (UKPDS) Group: Effect of intensive blood-glucose control with metformin on complications in overweight patients with type 2 diabetes (UKPDS 34). Lancet 1998;352:854-865.

14 UK Prospective Diabetes Study (UKPDS) Group: Intensive blood-glucose control with sulphonylureas or insulin compared with conventional treatment and risk of complications in patients with type 2 diabetes (UKPDS 33). Lancet 1998;352:837-853.

15 Fath-Ordoubadi F, Beatt KJ: Glucose-insulin-potassium therapy for treatment of acute myocardial infarction: an overview of randomized placebo-controlled trials. Circulation 1997;96:1152-1156.

16 Diaz R, Paolasso EA, Piegas LS, Tajer CD, Moreno MG, Corvalan R, Isea JE, Romero G: Metabolic modulation of acute myocardial infarction. The ECLA (Estudios Cardiologicos Latinoamerica) Collaborative Group. Circulation 1998;98:2227-2234.

- 17 Malmberg K, Norhammar A, Wedel H, Ryden L: Glycometabolic state at admission: important risk marker of mortality in conventionally treated patients with diabetes mellitus and acute myocardial infarction: long-term results from the Diabetes and Insulin-Glucose Infusion in Acute Myocardial Infarction (DIGAMI) study. Circulation 1999;99:2626-2632.

18 Malmberg K, Ryden L, Wedel H, Birkeland K, Bootsma A, Dickstein K, Efendic S, Fisher M, Hamsten A, Herlitz J, Hildebrandt P, MacLeod K, Laakso M, Torp-Pedersen C, Waldenstrom A: Intense metabolic control by means of insulin in patients with diabetes mellitus and acute myocardial infarction (DIGAMI 2): effects on mortality and morbidity. Eur Heart J 2005;26:650-661.

19 Filipovic M, Jeger RV, Girard T, Probst C, Pfisterer M, Gurke L, Studer W, Seeberger MD: Predictors of long-term mortality and cardiac events in patients with known or suspected coronary artery disease who survive major non-cardiac surgery. Anaesthesia 2005;60:5-11.
20 Filipovic M, Jeger RV, Probst C, Girard T, Pfisterer M, Gürke L, Skarvan K, Seeberger MD: Heart rate variability and cardiac troponin I are incremental and independent predictors of one-year all-cause mortality after major noncardiac surgery in patients at risk of coronary artery disease. J Am Coll Cardiol 2003;42:1767-1776.

-21 van den Berghe G, Wouters PJ, Bouillon R, Weekers F, Verwaest C, Schetz M, Vlasselaers D, Ferdinande P, Lauwers P: Outcome benefit of intensive insulin therapy in the critically ill: insulin dose versus glycemic control. Crit Care Med 2003;31:359-366.

22 Dandona P, Aljada A, Mohanty P: The antiinflammatory and potential anti-atherogenic effect of insulin: a new paradigm. Diabetologia 2002;45:924-930.

$\checkmark 23$ Apstein CS: The benefits of glucose-insulinpotassium for acute myocardial infarction (and some concerns). J Am Coll Cardiol 2003;42:792-795.

24 Cleveland JC Jr, Meldrum DR, Cain BS, Banerjee A, Harken AH: Oral sulfonylurea hypoglycemic agents prevent ischemic preconditioning in human myocardium. Two paradoxes revisited. Circulation 1997;96:29_ 32.

25 Mangano DT, Browner WS, Hollenberg M, Li J, Tateo IM: Long-term cardiac prognosis following cardiac surgery. The Study of Perioperative Ischemia Research Group. JAMA 1992;268:233-239.

26 Raby KE, Goldman L, Creager MA, Cook EF, Weisberg MC, Whittemore AD, Selwyn AP: Correlation between preoperative ischemia and major cardiac events after peripheral vascular surgery. N Engl J Med 1989;321: 1296-1300.

-27 Krupski WC, Layug EL, Reilly LM, Rapp JH, Mangano DT: Comparison of cardiac morbidity rates between aortic and infrainguinal operations: two-year follow-up. Study of Perioperative Ischemia Research Group. J Vasc Surg 1993;18:609-615; discussion 607615.

28 Hassan SA, Hlatky MA, Boothroyd DB, Winston C, Mark DB, Brooks MM, Eagle KA: Outcomes of noncardiac surgery after coronary bypass surgery or coronary angioplasty in the Bypass Angioplasty Revascularization Investigation (BARI). Am J Med 2001;110:260-266 